\title{
Postoperative Pain Experience and Satisfaction with Pain Control Medication among Surgical Patients
}

\author{
Abeer Mohamed EL-Shatby Moursy, Assistant Professor \\ Medical Surgical Nursing, Faculty of Nursing, Alexandria University \\ Hoda Abdou Abd El-Monem El-Deeb, Lecturer \\ Medical Surgical Nursing, Faculty of Nursing, Alexandria University
}

\begin{abstract}
Postoperative pain is profoundly prevalent and keeps on being a noteworthy challenge in the surgical patients' care. Objective: Assess the postoperative pain experience and satisfaction with pain control medication among surgical patients. Setting: The study was preceded in four surgical departments at Alexandria Main University Hospital. Subjects: A convenience sample of 135 adult patients who had undergone surgical operations throughout the $1^{\text {st }} 24$ hours. Tools: One tool was used to collect the necessary data: postoperative patient pain experience and satisfaction questionnaire. Results: The majority of patients had severe pain with severe percent score of (90.9\%). More than half of patients had severe impacted of pain on activities, sleep, mood and emotional status with moderate percent score of $(70.8 \%)$. More than three quarters of patients were moderate side effects of pain control medications. Conclusion: The study concluded that the majority of enrolled patients experienced severe pain in the $1^{\text {st }} 24$ hours postoperative and were not satisfied with pain control medication. Recommendations: This study recommended that nurses must appreciate the importance of effective pain evaluation, provide knowledge about postoperative pain control and ensure patients' participation in decisions of pain management.
\end{abstract}

Kevwords: Pain experience; Satisfaction; Pain control medication; Postoperative patient.

\section{Introduction}

Postoperative pain is the most prevalent complaints in surgical wards. It keeps on being a noteworthy challenge in the management of surgical patients ${ }^{(1,2)}$. Despite all the available analgesics, most surgical patients still suffer from mild to intense pain after surgery. Inadequate pain management can prompt counter active physical and psychological patients outcomes $^{(1,2)}$. Several studies demonstrated that postoperative pain is common and pain control is inadequate ${ }^{(3,4)}$.

Over 230 million people undergo surgery each year worldwide and the number is increasing annually and up to $80 \%$ of patients experienced pain after surgery. Literature review suggests that postoperative pain remains a challenge in the developed and developing countries ${ }^{(5-8)}$. The study done by Sommer et al. (2008) reported that the prevalence of moderate or severe pain was high (30-55\%) among postoperative patients on the first day following surgery ${ }^{(9)}$.

Deficient pain management increases morbidity, mortality and decreased patients' quality of life. Also, it reduces patient mobility, resulting in postoperative complications including deep vein thrombosis, pneumonia and pulmonary embolus. All of these negatively affect the patient's welfare and the hospital performance in addition to extended lengths of stay and readmissions, both of which increase the cost of care ${ }^{(10,11)}$.

Unceasing, unrelieved pain also influences the patient's psychological condition. Prevalent psychological responses to pain include anxiety, helplessness, hopelessness and depression. Moreover, Patients who have experienced insufficient pain management may be reluctant to seek medical care for other health problems ${ }^{(1,7)}$. 
Patient satisfaction with care is strongly tied to their experiences with pain during hospitalization. Postoperative patient satisfaction has been appeared to be related to the level of pain control. Thus, availability of adequate postoperative pain control is needed ${ }^{(10-12)}$.

Pain is described as an annoying feel and psychological experience following surgery. It is thought to be caused by nerve injury, and neuroplastic change in the central nervous system induced by highintensity pain in the first days following surgery. Presently, pain literature bolsters the idea that even a brief experience of mild to intense acute pain can prompt neurons reorganization in the higher center ${ }^{(13,14)}$.

Pain management is an essential constituent in providing quality health-care planning and evaluation. Pain management guidelines seem to have had little effect on practice patterns or improvement in patients' pain control. Postoperative pain continues being known as an issue among patients $^{(15)}$. Inadequate treatment of postoperative pain can influence satisfaction level among patients, since pain control is known to be the essential effectiveness measure of pain management system ${ }^{(16,17)}$.

Nowadays, the recognition and treatment of pain among post-surgical patients has recently received increased attention. The American Pain Society Standards advocate that pain is appraised in all patients and that patients have the right to appropriate appraisal and management ${ }^{(18,19)}$.So, this study expects to provide insight into patients' pain encounter instantly on the first 24 hours of surgery, and to investigate satisfaction with pain control medication among surgical patients.

\section{Aim of the Study}

This study aimed to assess the postoperative pain experience and satisfaction with pain control medication among surgical patients.

\section{Research Question}

What is the postoperative pain experience and satisfaction with pain control medication among surgical patients?

\section{Operational definition:}

Pain experience is defined as feeling of pain due to major or minor surgery that impacted on patients activities, sleep, mood and emotion status throughout the first 24 hours postoperatively.

\section{Materials and Method}

\section{Materials}

Design: A descriptive study design was used.

Setting: The study was preceded in four surgical departments at Alexandria Main University Hospital, namely the Neurosurgery, Hepatobiliary, Gastrointestinal and Cancer surgery Departments.

Subjects: The study subjects comprised a convenience sample of 135 adult male and female patients who had undergone surgical operations throughout the $1^{\text {st }} 24$ hours at the above mentioned settings.

The statistical program Epi-Info was used to estimate the sample size using the following parameters:

1) Population size $=720$ over 3 months

2) Expected frequency $=50 \%$

3) Acceptable error $=10 \%$

4) Confidence coefficient $=99 \%$

5) Sample size $=135$ patients

\section{Subjects' inclusion criteria:}

1. Adult patients, with age range from 21 years to 60 .

2. Able to communicate verbally

3. Willing to participate in the study

4. Had undergone elective or emergency surgery throughout $1^{\text {st }} 24$ hours.

5. Free from associated postoperative complications.

Tools: One tool was used to collect the necessary data: 


\section{Tool I: Postoperative Patient Pain Experience and Satisfaction Questionnaire}

It was adapted from the Revised American Pain Society's Patient Outcome Questionnaires (APS-POQ-R) (2010) ${ }^{(20)}$ and was used to measure pain experience and patient satisfaction to pain control medication post-surgery. The questionnaire consisted of 32 items and was split into three parts:

Part 1: This part includes 8 items about biosociodemographic and clinical data. It included age, sex, educational level, occupation, previous operation, categories of current operation, operation status and type of pain control medication prescribed during the first 24 hours post surgery.

Part 2: This part includes 17 items related to patient pain experience during the $1^{\text {st }} 24$ hours post-surgery, using 0-10 numeric rating scales. These items comprised pain severity (6 statements), pain interference with patient activities, sleep, mood and emotional status (7 statements) and (4 statements) side effects of pain control medications. The measured value is illustrated as none (0), mild (1-3), moderate (4-6) and severe (7-10). The total score of pain experience ranged from 17 to 170 . The total pain experience score summed and converted into percent was judged as the following: less than $50 \%$ categorized as mild pain experience, from $50 \%$ to less than $75 \%$ categorized as moderate pain experience and more than $75 \%$ categorized as severe pain experience.

Part 3: This part consists of 7 items related to satisfaction with pain control outcomes, decision \& information on the $1^{\text {st }} 24$ hours postoperatively, among surgical patients, these items are rated using a 2-point Likert scales ranging from not satisfied (1), and satisfied (2). The total score ranged from 7 to 14 . The total satisfaction score summed and converted into percent was judged as the following: less than $50 \%$ categorized as not satisfied and more or equal than $50 \%$ categorized as satisfied.

\section{Method}

- An official letter from Alexandria Faculty of Nursing was submitted to the general director of the surgical departments of the Main University Hospital. Permission to carry out the study was secured after complete explanation of the study aim.

- The developed tool was tested for content validity by five experts in the field of Medical Surgical Nursing. The required corrections and modifications were introduced accordingly.

- Reliability of the tool was established using Cronbach's Alpha test ( $\mathrm{r}=0.799)$.

- A pilot study was carried out on $10 \%$ of the sample to ensure the clarity, applicability, relevance, and feasibility of the tool. Necessary modifications were done prior to data collection for the actual study and those patients were excluded from the study sample.

- Every patient was interviewed individually once at the inpatient surgical ward at morning shift after the $1^{\text {st }} 24 \mathrm{hrs}$ post surgery to identify patients pain experience and their level of satisfaction with pain control medication. Each interview lasted for around 20 to 25 minutes by using tool I.

- Data were collected throughout a period of 6 months from August 2017 to end of January 2017.

\section{Ethical considerations:}

Written consents were obtained from patients after explanation of the aim of the study. Confidentiality and privacy of collected data were assured. Anonymity and right to withdraw from the study was respected.

\section{Statistical Analysis}

After data collection, data were fed to the computer and analyzed using Statistical Package for Social Sciences (SPSS) version 20. Raw data was coded and scored and a coding instruction manual was prepared. 
Qualitative data were described using number and percent. Quantitative data were described using mean, standard deviation. Significance of the obtained results was judged at the $5 \%$ level.

\section{The used tests were:}

- Chi-square test: For categorical variables, to compare between different groups

- Fisher's Exact or Monte Carlo correction: Correction for chi-square when more than $20 \%$ of the cells have expected count less than 5 .

\section{Results}

Table (1) shows frequency distribution of patients related to biosocio-demographic and clinical characteristics among the studied surgical patients. The results revealed that $44.4 \%$ of the studied patients were between 31 to less than 41years old. The highest percentage of patients $(77 \%)$ was females. Less than half of patients $(45.9 \%)$ had primary education. Also, it was noticed that more than two thirds $(69.6 \%)$ were house wife and $68.1 \%$ had a history of previous operations. The majority of the studied patients $(98.5 \%)$ had undergone major surgeries and nearly three quarters $(74.07 \%)$ their operations were elective. Also, the table revealed that less than half of the sample (43\%) had prescribed NSAIDs and paracetamol intravenously to control their pain. Whereas $(38.5 \%)$ of subjects had been prescribed NSAIDs, only.

Table (2) represents Pain experience related to pain severity on the $1^{\text {st }} 24$ hours postoperatively among the enrolled surgical patients. In relation to the least pain at rest, most subjects (45.9\%) had reported moderate pain. Whereas, the worst pain at rest they described as being severe by the majority (92.6\%) of the studied patients. Forty eight point nine percent of patients had experienced severe pain during rest. More than two thirds (68.9\%); had experienced severe pain, which was the least during movement. The majority $(92.6 \%)$ had reported severe pain described as being the worst pain during movement. As regards to percent of severe pain during movement the majority $(83.7 \%)$ were severe.

Table (3) displays Pain experience related to impact of pain on activities, sleep, mood and emotional status on the $1^{\text {st }} 24$ hours post operative among the enrolled surgical patients. Most patients $(45.1 \%$ \& $91.1 \%$ ) reported severe pain that interfered with in and out of bed activities, respectively. Nearly three quarters $(74.1 \%)$ had reported that severe pain interfered with falling asleep. Also the table showed that over half $(57 \%)$ of patients reported feeling moderately anxious due to pain, over one third $(39.3 \%)$ felt mildly frightened and more than two fifths $(43.7 \%)$ felt moderately helpless while, the majority $(80 \%)$ felt neutral depressed.

Table (4) shows frequency distribution of patients in relation to side effects of pain control medication on the $1^{\text {st }} 24$ hours postoperative among surgical patients. Over half $(58.5 \%)$ of the subjects complained of moderate nausea, nearly three fifths $(60.7 \%)$ had moderate drowsiness, the majority $(81.5 \%)$ had mild itching and less than half $(47.4 \%)$ had moderate dizziness.

Table (5) illustrates overall percent score of pain experience in relation to pain severity, impact of pain and side effect of pain control medication among surgical patients during the $1^{\text {st }} 24$ hrs post operatively. In relation to pain severity; the majority of patients $(85.9 \%)$ had severe pain with severe percent score $(90.9 \%)$. More than half $(51.1 \%)$ of patients had severe impacted of pain on activities, sleep, mood and emotional status with moderate percent score $(70.8 \%)$. More than three quarters $(77.8 \%)$ of patients were moderate side effects of pain control medications with moderate percent score $(62.5 \%)$. Regarding overall percent score of pain experience revealed that more than three quarters (76.3\%) were experienced severe pain with severe percent score $(76 \%)$.

Table (6) demonstrates frequency distribution of patients related to 
satisfaction with pain control medication on the $1^{\text {st }} 24$ hours post surgery among surgical patients. All patients (100\%) were not satisfied with the response of doctors or nurses to pain complain, their participation in decisions of pain management, with information's received about pain control, with received information's about none medicine treatment or with encouragement of doctors or nurses to non-medicine method. $92.6 \%$ and $94.8 \%$ of patients were not satisfied with pain control outcomes and with decision about pain medication, respectively. The same table revealed that total satisfaction score to pain control medication was low $(0.7 \%)$ satisfied and high percent score (99.3\%) was not satisfied.

Table (7) shows relation between postoperative pain control medications and pain experience. The results revealed that there was a highly significant effect of narcotics with NSAIDs on mild pain experience, than NSAIDs only and NSAIDs with paracetamol on severe pain.

\section{Discussion}

Effective postoperative pain management is a major concern to health care experts $^{(21)}$. It is not just providing pain relief but also diminishes morbidity, facilitates quick recuperation and decreases hospital stay length. The WHO considers pain relief as a human right and recommends continuing measurements of postoperative pain to guarantee quality and patients' satisfaction ${ }^{(22)}$.

The study findings have shown that the overall percent score of postoperative pain experience was severe in the first 24 hours post surgery. This finding is supported by Subramanian et al. (2016) revealed that the majority of postoperative patients had experienced severe pain in the $1^{\text {st }} 24$ hours postoperatively $^{(23)}$. In relation to pain severity, majority of studied patients experienced severe pain on the $1^{\text {st }} 24$ hours post surgery at rest and during movement. This may be attributed to the mechanism of pain caused by surgical tissue trauma which leads to activation and sensitization of peripheral nociceptors and spinal dorsal horn neurons ${ }^{(24)}$. As a result, individuals suffer ongoing pain at rest and during movement. Similar, findings have been reported by Philip et al. (2017) who stated that postoperative pain outcomes from tissue injury during surgical procedure like tissue dissection, skin incision, traction and manipulation $^{(25)}$.

Regarding to impact of pain on activities, sleep, mood and emotional status. The results of the present study indicated that the majority of patients experienced severe pain that interfered with in and out of bed activities. No doubt fear of the movement in or out of bed due to surgical incision and attached tubes leads to muscular tension that exaggerates pain perceived. Karabulut et al. (2011) who reported that all of their studied patients revealed similar findings ${ }^{(26)}$. Also, the findings of current study revealed that most of the studied patients reported that their pain interfered with falling to sleep. This result is in line with Abdel-Hameed (2015) who reported that most of their surgical patient's experienced severe pain which interfered with sleep ${ }^{(27)}$.

Moreover, the findings of the present study showed that majority of the studied patients reported that moderate pain caused them feeling anxious, and helpless. This may be due to the type of surgery. Patients who had major surgeries were found to experience more pain and anxiety postsurgery compared to others who had other types of surgery. These results agree with Woldehaimanot et al. (2014) since they indicated that there were statistical significant correlations between type of surgery a patient underwent with the postoperative perceived pain and anxiety over the first 3 days post surgery ${ }^{(28)}$. In this context, Subramanian et al. (2017) indicated that most of the patients in their study reported that they were severely anxious and helplessness due to postoperative pain $^{(29)}$.

Concerning pain control medication prescribed on the $1^{\text {st }} 24$ hours postoperative, the majority of postoperative patients in the current study received combinations of 
analgesia as nonsteroidal anti- inflammatory drugs (NSAIDs) and paracetamol intravenously to control pain with moderate side effects as nausea, drowsiness and dizziness. These results are supported by the American Pain Society (2016) which recommended a combination of paracetamol and nonsteroidal antiinflammatory drugs (NSAIDs) as part of multimodal analgesia for management of postoperative pain. Paracetamol and NSAIDs have different action mechanisms and might be more efficient than either drug alone $^{(19)}$. It has been indicated that administration of analgesic intravenously had faster action than intramuscularly ${ }^{(30,31)}$. The principle issue with intramuscular course of analgesia is the unpredictable drugs absorption, reduced peripheral perfusion and subsequently uptake of analgesia from muscles is prolonged. Also, paracetamol has minimal adverse side effects and NSAIDS have been related with significant gastrointestinal, cardiovascular, renal, and coagulopathy adverse effects.

The present study findings revealed that the most of enrolled patients were not satisfied with pain control outcome, response of doctors or nurses to pain complains, participation in decisions of pain treatment and with information received about pain control. These patients dissatisfaction may be related to insufficient preoperative education and absence of effective communication between patients and health care providers. This result is in agreement with a study done by Aly (2013) who revealed that the majority of postoperative patients were dissatisfied with pain management ${ }^{(32)}$. On the contrary, Subramanian et al. (2017) declared that the majority of participants were satisfied with all aspects of the pain treatment they received. These results are due to therapeutic communication between patients and care providers which is important for effective medical practice and help to establish trust between patient and care providers ${ }^{(29)}$. Comparable findings have been shown by Yorke et al. (2004) who demonstrated patient's satisfaction with pain management after cardiac surgery and they referred that to information received about pain management ${ }^{(33)}$.

Moreover, the current study revealed that there was a highly significant effect of narcotics with NSAIDs on mild pain experience than NSAIDs only and NSAIDs with paracetamol on severe pain. This is may be contributed to the majority of prescribed post-operative pain control medications was nonopioid medications and this is not adequate. This results is supported by Angst et al. (2012) who reported that the effective acute pain management post operatively must consists of both opioid and non-opioid medications ${ }^{(34)}$. Also, this results are in line with Stephan and Parsa (2016) concluded that narcotics with NSAIDs are more effective combination for pain control medication post surgery in spite of having critical unfavorable effects including nausea, constipation, vomiting, dizziness, excessive sedation, clouded sensorium, respiratory depression, and addiction ${ }^{(35)}$. So, the pain control medication prescribed for postoperative patient should be modified in order to optimize their pain control effect and satisfaction.

\section{Conclusion}

It can be concluded that the majority of the patient's experienced severe pain on the $1^{\text {st }}$ 24 hours post surgery that impacted on activities in and out of bed, sleep, mood and emotional status. Also, most of the enrolled patients were not satisfied with pain control medication.

\section{Recommendations}

- Nurses must appreciate the importance of effective pain assessment to determine patient's pain experience after surgery.

- Patients must obtain information about postoperative pain control medication.

- Patients must participate in decisions of pain control management.

- Careful use of a variety of analgesic medications combined with nonpharmacological interventions, for managing postoperative pain as acupuncture, massage, or cold therapy, could be advocated. 
Table (1): Frequency distribution of patients in relation to biosocio-demographic and clinical characteristics among surgical patients $(\mathrm{N}=135)$

\begin{tabular}{|c|c|c|}
\hline $\begin{array}{l}\text { Biosocio-demographic and clinical } \\
\text { characteristics }\end{array}$ & No. & $\%$ \\
\hline $\begin{array}{l}\text { Age (years) } \\
21- \\
31- \\
41- \\
51 \geq 60\end{array}$ & $\begin{array}{l}28 \\
60 \\
23 \\
24\end{array}$ & $\begin{array}{l}20.7 \\
44.4 \\
17.0 \\
17.8\end{array}$ \\
\hline $\begin{array}{l}\text { Sex } \\
\text { Male } \\
\text { Female } \\
\end{array}$ & $\begin{array}{c}31 \\
104\end{array}$ & $\begin{array}{l}23.0 \\
77.0\end{array}$ \\
\hline $\begin{array}{l}\text { Educational level } \\
\text { Illiterate/read and write } \\
\text { Primary } \\
\text { Secondary } \\
\text { Diploma } \\
\text { University } \\
\end{array}$ & $\begin{array}{l}25 \\
62 \\
21 \\
17 \\
10 \\
\end{array}$ & $\begin{array}{l}18.5 \\
45.9 \\
15.6 \\
12.6 \\
7.4 \\
\end{array}$ \\
\hline $\begin{array}{l}\text { Occupation } \\
\text { Private work } \\
\text { Clerical } \\
\text { Retired } \\
\text { House wife }\end{array}$ & $\begin{array}{c}29 \\
2 \\
10 \\
94\end{array}$ & $\begin{array}{c}21.5 \\
1.5 \\
7.4 \\
69.6\end{array}$ \\
\hline $\begin{array}{l}\text { Previous operation } \\
\text { Yes } \\
\text { No } \\
\end{array}$ & $\begin{array}{l}92 \\
43 \\
\end{array}$ & $\begin{array}{l}68.1 \\
31.9 \\
\end{array}$ \\
\hline $\begin{array}{l}\text { Categories of current operation } \\
\text { Minor } \\
\text { Major }\end{array}$ & $\begin{array}{c}2 \\
133 \\
\end{array}$ & $\begin{array}{c}1.5 \\
98.5 \\
\end{array}$ \\
\hline $\begin{array}{l}\text { Operation status } \\
\text { Elective } \\
\text { Emergency }\end{array}$ & $\begin{array}{c}100 \\
35\end{array}$ & $\begin{array}{l}74.07 \\
25.93\end{array}$ \\
\hline $\begin{array}{l}\text { Postoperative pain control medications } \\
\text { prescribed in the } 1^{\text {st }} \mathbf{2 4 h o u r s} \\
\text { NSAIDS } \\
\text { Paracetamol } \\
\text { NSAIDs }{ }^{\#} \& \text { Paracetamol } \\
\text { Antimuscarinic \& Paracetamol } \\
\text { Narcotic \& NSAIDs }\end{array}$ & $\begin{array}{c}52 \\
6 \\
58 \\
9 \\
10\end{array}$ & $\begin{array}{c}38.5 \\
4.4 \\
43.0 \\
6.7 \\
7.4 \\
\end{array}$ \\
\hline
\end{tabular}


Table (2): Pain experience related to pain severity on the $1^{\text {st }} 24$ hours postoperatively among the enrolled surgical patients

\begin{tabular}{||l|c|c|c|c|c|c|c|c||}
\hline \multirow{2}{*}{ Items of pain experience } & \multicolumn{2}{|c|}{ Severe } & \multicolumn{2}{c|}{ Moderate } & \multicolumn{2}{c|}{ Mild } & \multicolumn{2}{c|}{ None } \\
\cline { 2 - 10 } & $\mathbf{N o}$ & $\%$ & $\mathbf{N o}$ & $\%$ & No & $\%$ & No & $\%$ \\
\hline $\begin{array}{l}\text { The least pain the patient had on the first 24 } \\
\text { hours post operative at rest }\end{array}$ & 53 & 39.3 & 62 & 45.9 & 20 & 14.8 & 0 & 0.0 \\
\hline The worst pain on the first 24 hours at rest & 125 & 92.6 & 10 & 7.4 & 0 & 0 & 0 & 0.0 \\
\hline $\begin{array}{l}\text { Percent of severe pain during rest on the } \\
\text { first 24 hours post operative. }\end{array}$ & 66 & 48.9 & 59 & 43.7 & 10 & 7.4 & 0 & 0.0 \\
\hline $\begin{array}{l}\text { The least pain the patient had on the first 24 } \\
\text { hours during movement. }\end{array}$ & 93 & 68.9 & 22 & 16.3 & 20 & 14.8 & 0 & 0.0 \\
\hline $\begin{array}{l}\text { The worst pain the patient had on the first } \\
\text { 24 hours during movement. }\end{array}$ & 125 & 92.6 & 10 & 7.4 & 0 & 0.0 & 0 & 0.0 \\
\hline $\begin{array}{l}\text { Percent of severe pain during movement on } \\
\text { the first 24 hours post operative. }\end{array}$ & 113 & 83.7 & 13 & 9.6 & 9 & 6.7 & 0 & 0.0 \\
\hline
\end{tabular}

Table (3): Pain experience related to impact of pain on activities, sleep, mood and emotional status on the $1^{\text {st }} \mathbf{2 4}$ hours post operative among the enrolled surgical patients

\begin{tabular}{||l|c|c|c|c|c|c|c|c||}
\hline \multirow{2}{*}{ Impact of pain } & \multicolumn{2}{|c|}{ Severe } & \multicolumn{2}{c|}{ Moderate } & \multicolumn{2}{c|}{ Mild } & \multicolumn{2}{c|}{ None } \\
\cline { 2 - 11 } & No & $\mathbf{\%}$ & No & $\mathbf{\%}$ & No & $\mathbf{\%}$ & No & $\%$ \\
\hline $\begin{array}{l}\text { Pain interferes with doing activities in } \\
\text { bed }\end{array}$ & 61 & 45.1 & 43 & 31.9 & 21 & 15.6 & 10 & 7.4 \\
\hline $\begin{array}{l}\text { Pain interferes with doing activities out } \\
\text { of bed }\end{array}$ & 123 & 91.1 & 12 & 8.9 & 0 & 0.0 & 0 & 0.0 \\
\hline Pain interferes with falling sleep & 99 & 74.1 & 25 & 18.5 & 10 & 7.4 & 0 & 0.0 \\
\hline Pain caused you feel anxious & 19 & 14.1 & 77 & 57 & 29 & 21.5 & 10 & 7.4 \\
\hline Pain caused you feel depressed. & 0 & 0.0 & 0 & 0.0 & 27 & 20 & 108 & 80 \\
\hline Pain caused you feel frightened. & 0 & 0.0 & 47 & 34.8 & 53 & 39.3 & 35 & 25.9 \\
\hline Pain caused you feel helpless. & 25 & 18.6 & 59 & 43.7 & 31 & 23 & 20 & 14.8 \\
\hline
\end{tabular}

Table (4): Frequency distribution of patients in relation to side effects of pain control medications on the $1^{\text {st }} 24$ hours post operative among the surgical patients

\begin{tabular}{|c|c|c|c|c|c|c|c|c|}
\hline \multirow{2}{*}{$\begin{array}{l}\text { Side effects that the patient had in } \\
\text { the } 1^{\text {st } 24 \text { hours postoperatively }}\end{array}$} & \multicolumn{2}{|c|}{ Severe } & \multicolumn{2}{|c|}{ Moderate } & \multicolumn{2}{|c|}{ Mild } & \multicolumn{2}{|c|}{ None } \\
\hline & No & $\%$ & No & $\%$ & No & $\%$ & No & $\%$ \\
\hline Nausea & 26 & 19.3 & 79 & 58.5 & 20 & 14.8 & 10 & 7.4 \\
\hline Drowsiness & 4 & 3 & 82 & 60.7 & 30 & 22.2 & 19 & 14.1 \\
\hline Itching & 0 & 0.0 & 0 & 0.0 & 110 & 81.5 & 25 & 18.5 \\
\hline Dizziness & 25 & 18.5 & 64 & 47.4 & 36 & 26.7 & 10 & 7.4 \\
\hline
\end{tabular}


Table (5): Overall percent score of pain experience in relation to pain severity, impact of pain and side effect of pain control medication among surgical patients

\begin{tabular}{||l|c|c|c|c|c|c|c|c||}
\hline \multirow{2}{*}{ Items } & \multirow{2}{*}{$\begin{array}{c}\text { Total } \\
\text { score }\end{array}$} & \multirow{2}{*}{$\%$ score } & \multicolumn{2}{|c|}{ Mild } & \multicolumn{2}{c|}{ Moderate } & \multicolumn{2}{c|}{ Severe } \\
\cline { 4 - 9 } & $21.8 \pm 2.7$ & $90.9 \pm 11.2$ & 0 & 0.0 & 19 & 14.1 & 116 & 85.9 \\
\hline Pain severity & $19.8 \pm 3.4$ & $70.8 \pm 12.2$ & 10 & 7.4 & 56 & 41.5 & 69 & 51.1 \\
\hline $\begin{array}{l}\text { Impact of pain on activities, } \\
\text { sleep, mood and emotional } \\
\text { status }\end{array}$ & & & & & & & & \\
\hline $\begin{array}{l}\text { Side effects of pain control } \\
\text { medication }\end{array}$ & $10.0 \pm 2.0$ & $62.5 \pm 12.8$ & 20 & 14.8 & 105 & 77.8 & 10 & 7.4 \\
\hline $\begin{array}{l}\text { Overall percent score of } \\
\text { Pain experience }\end{array}$ & $51.7 \pm 7.6$ & $76.0 \pm 11.2$ & 10 & 7.4 & 22 & 16.3 & 103 & 76.3 \\
\hline
\end{tabular}

Table (6): Frequency distribution of patients related to satisfaction with pain control medication on the $1^{\text {st }} 24$ hours post surgery among surgical patients

\begin{tabular}{||l|c|c|c|c||}
\hline \multirow{2}{*}{ Items } & \multicolumn{2}{|c|}{ Satisfied } & \multicolumn{2}{c|}{ Not satisfied } \\
\cline { 2 - 5 } & No & $\mathbf{\%}$ & No & \% \\
\hline Response of doctors or nurses to pain complain & 0 & 0.0 & 135 & 100.0 \\
\hline Outcome of pain control & 10 & 7.4 & 125 & 92.6 \\
\hline Participation of patient in decisions of pain treatment. & 0 & 0.0 & 135 & 100.0 \\
\hline Decision about pain medication & 7 & 5.2 & 128 & 94.8 \\
\hline Received information about pain control & 0 & 0.0 & 135 & 100.0 \\
\hline Received information's about none medicine treatment & 0 & 0.0 & 135 & 100.0 \\
\hline $\begin{array}{l}\text { Encouragement of doctors or nurses to non medicine } \\
\text { method }\end{array}$ & 0 & 0.0 & 135 & 100.0 \\
\hline Total score & $\mathbf{1}$ & $\mathbf{0 . 7}$ & $\mathbf{1 3 4}$ & $\mathbf{9 9 . 3}$ \\
\hline
\end{tabular}

Table (7): Relation between postoperative pain control medications and Pain experience on the $1^{\text {st }} 24$ hours post surgery among surgical patients

\begin{tabular}{|c|c|c|c|c|c|c|c|c|}
\hline \multirow{3}{*}{$\begin{array}{l}\text { Postoperative pain control } \\
\text { medications }\end{array}$} & \multicolumn{6}{|c|}{ Overall Pain experience } & \multirow{3}{*}{$\chi^{2}$} & \multirow{3}{*}{ (P value) } \\
\hline & \multicolumn{2}{|c|}{ Mild 10} & \multicolumn{2}{|c|}{ Moderate 22} & \multicolumn{2}{|c|}{ Severe 103} & & \\
\hline & $\mathbf{n}$ & $(\%)$ & $\mathbf{n}$ & $(\%)$ & n & $(\%)$ & & \\
\hline NSAIDS $^{\#}$ & 0 & 0.0 & 12 & 23.1 & $\overline{40}$ & 76.9 & $8.656^{*}$ & $0.013^{*}$ \\
\hline Paracetamol & 0 & 0.0 & 0 & 0.0 & 6 & 100.0 & 0.837 & $\begin{array}{l}{ }^{\mathrm{MC}} \mathrm{p}= \\
0.741\end{array}$ \\
\hline NSAIDs $^{\#} \&$ Paracetamol & 0 & 0.0 & 10 & 17.2 & 48 & 82.8 & $8.145^{*}$ & $0.017^{*}$ \\
\hline Antimuscarinic\&Paracetamol & 0 & 0.0 & 0 & 0.0 & 9 & 100.0 & 1.799 & $\begin{array}{l}{ }^{\mathrm{MC}} \mathrm{p}= \\
0.438\end{array}$ \\
\hline Narcotic \& NSAIDs ${ }^{\#}$ & 10 & 100.0 & 0 & 0.0 & 0 & 0.0 & $63.774^{*}$ & $<0.001^{*}$ \\
\hline
\end{tabular}

${ }^{\#}$ NonsteroidalAntinflammatory drugs $\quad \chi^{2}$ : Chi square test. $\quad$ MC: Monte Carlo $\quad$ *: Statistically significant at $p \leq 0.05$ 


\section{References}

1. McIntosh S. and Adams J. Anxiety and quality of recovery in day surgery: A questionnaire study using Hospital Anxiety and Depression Scale and Quality of Recovery Score. International Journal of Nursing Practice. 2011; 17(1):85-92.

2. Czarnecki M., Turner H., Collins P., Doellman D., Wrona S. and Reynolds J. Procedural pain management: A position statement with clinical practice recommendations. Pain Management Nursing. 2011; 12(2):95-111.

3. Maiyo J. Barriers to pain management among patients with advanced breast cancer. Master Thesis, Faculty of Nursing, Alexandria University, Egypt2018.

4. Biomy H, Nurses perception of acute and chronic pain management barriers among patients suffering from cancer. Master Thesis, Faculty of Nursing, Alexandria University, Egypt 2016.

5. Weiser T., Regenbogen S., Thompson K., Haynes A., Lipsitz S., Berry W., Gawande A. An estimation of the global volume of surgery: a modelling strategy based on available data. Lancet 2008; 372:139 - 44.

6. National Center for Health Statistics. Number of all-listed procedures from discharges from short-stay hospitals by procedure category and age: United States, 2009.

7. Atlanta G. Centers for Disease Control and Prevention, Available at: http://www.cdc.gov/nchs/data/nhds/4proce dures/2009pro4_numberprocedureage.pdf. Accessed: September 12, 2012.

8. Fletcher D., Fermanian C., Mardaye A., Aegerter P: A patient-based national survey on postoperative pain management in France reveals significant achievements and persistent challenges. Pain J 2008.137: 441-51.
9. Sommer M., de Rijke J., van KleefMet al. The prevalence of postoperative pain in a sample of 1490 surgical inpatients. Journal of Anaesthesiology 2008; 254: 267-74.

10. Jawaid M., Muhammad S., Shafiq F., Malik K. Acute post- operative pain European management by a surgical team in a tertiary care hospital: Patients' satisfaction. Middle East Journal of Anesthesiology 2009;203: 405-10.

11. Bedard D., Purden M., Sauve-Larose, N., Certosini, C. and Schein, C. The pain experience in post surgical patients following the implementation of an evidence-based approach. Pain Management Surgery 2006.7(3):80-92.

12. Leegaard M., Naden, D. and Fagermoen M. Postoperative pain and selfmanagement: Women's experiences after cardiac surgery. Journal of Advanced Nursing 2008.63(5):476-85.

13. Taylor A. and Stanbury L. A review of postoperative pain management and the challenges. Current Anaesthesia\& Critical Care 2009.20(4):188-94.

14. Walker J. Patient information. What is the effect of preoperative information on patient satisfaction? British Journal of Nursing 2007; 16(1):27-32.

15. Brown C., Constance K.., Bedard D., Purden M. Colorectal surgery patients' pain status, activities, satisfaction, and beliefs about pain and pain management. Pain Management Nursing 2013; 14(4):184-92.

16. Czarnecki L., Turner H., Collins P., Doellman D., Wrona S. and Reynolds J. Procedural pain management: A position statement with clinical practice recommendations. Pain Management Nursing 2011; 12(2):95-111.

17. Fletcher D., Pogatzki-Zahn E., Zaslansky R., Meissner W., the Pain Out 
Group:euCPSP: European observational study on chronic post-surgical pain. European Journal of Anaesthesiology 2011; 28: 461-462,

18. Coluzzi F., Bragazzi L., Di Bussolo E., Pizza G. and Mattia C. Determinants of patient satisfaction in postoperative pain management following hand ambulatory day-surgery. Minerva Medica Journal 2011; 102: 177-86.

19. Chou R., Gordon D., de Leon-Casasola O., Rosenberg J., Bickler S., Brennan T. Management of Postoperative Pain: clinical practice guideline from the American pain society, the American Society of Regional Anesthesia and Pain Medicine, and the American Society of Anesthesiologists' committee on regional anesthesia, executive committee, and administrative council. The Journal of Pain 2016; 1; 7(2):131-57.

20. Gordon D., Polomano R., Pellino T., Turk D., McCracken L., Sherwood G., Paice J., Wallace M., Strassels S., Farrar J. Revised American Pain Society Patient Outcome Questionnaire (APS-POQ-R) for quality improvement of pain management in hospitalized adults: preliminary psychometric evaluation. The Journal of Pain 2010; 11(11):1172-86.

21. Manias E., Bucknall T. Patients' decision making strategies for managing postoperative pain. The Journal of Pain 2006; 7(6): 428-37.

22. Garimella V. and Cellini C. Postoperative pain control. Clinics of Colon Rectal Surgery 2013; 26: 191-6.

23. Subramanian P., Ramasamy S., Hoong K. and Chinna K. Pain experience and satisfaction with postoperative pain control among surgical patients International Journal of Nursing Practice 2016; 22: 2328.
24. Hayashida K., DeGoes S., Curry R, Eisenach J. Gabapentin activates spinal noradrenergic activity in rats and humans and reduces hypersensitivity after surgery. Anesthesiology Journal 2007; 106: 55762.

25. Philip W., Schroeder R. The postoperative care of the surgical patient. International Journal of Pharmacy 2017:93-97.

26. Karabulut N, Yilmaz D. Patient satisfaction with their pain management and comfort level after open heart surgery. Australian Journal of Advanced Nursing 2011; 32 (3):16-24.

27. Abdel-Hameed I., Ebid M. and Adel S. Physician-Pharmacist Co management of Postoperative Pain in Egyptian Patients: Patient Controlled Analgesia Using Morphine versus Nalbuphine. Tanzania Journal of Health Research 2015; 5(9): 0116.

28. Woldehaimanot T., Eshetie T.and Kerie M. Postoperative Pain Management among Surgically Treated Patients in an Ethiopian Hospital. Pupmed Journal 2014; 9(7).

29. 29. Subramanian B., Lutful Aziz L, Gopinath R. Patient satisfaction survey in postoperative pain management from Indian subcontinent. Journal of Anesthesiology Clinical Pharmacology 2017; 33(1): 40-7.

30. Brett C., Barnett S. and Pearson J: Postoperative plasma paracetamol levels following oral or intravenous paracetamol administration: A double-blind randomised controlled trial. Anesthesiology Intensive Care Journal 2012; 40:166-71.

31. Chung F. Postoperative symptoms 24 hours after ambulatory anaesthesia. Available at: https://www.ncbi.nlm.nih.gov/pubmed/892 2767. Retrieved on August 2018. 
32. Aly S. Barriers to pain management as perceived by nurses working at surgical units. Alexandria Scientific Nursing Journal 2013; 5(2):133-43.

33. Yorke J., Grad D., Wallis M., McLean B, Cert G. Patients' perceptions of pain management after cardiac surgery in an Australian critical care unit. Journal of Heart and Lung 2004; 33(1):33-41.

34. Angst M., Lazzeroni L., Phillips N., Drover D, Tingle M. Aversive and reinforcing opioid effects: A pharmacogenomic twin study. Anesthesiology Journal 2012; 117 (1):22-37.

35. Stephan B., Parsa F. Avoiding opioids and their harmful side effects in the postoperative patient: exogenous opioids, endogenous endorphins, wellness, mood, and their relation to postoperative pain.Hawai'i Journal of Medicine \& Public Health 2016; 75(3):63. 